\title{
Accidental tramline bruising and rib fractures
}

\author{
Giles N. Cattermole
}

Received: 8 September 2009 /Accepted: 23 November 2009/Published online: 27 February 2010

(C) Springer-Verlag London Ltd 2010

\section{Description}

A 37-year-old, 85-kg man fell from his bicycle landing on his left chest. Fractures of the fifth and sixth ribs were diagnosed clinically and with ultrasound. Bruising developed after a few days in a tramline, linear pattern with three stripes outlining the affected ribs (Figs. 1 and 2). Tramline bruising is often presumed to be caused by blows with a

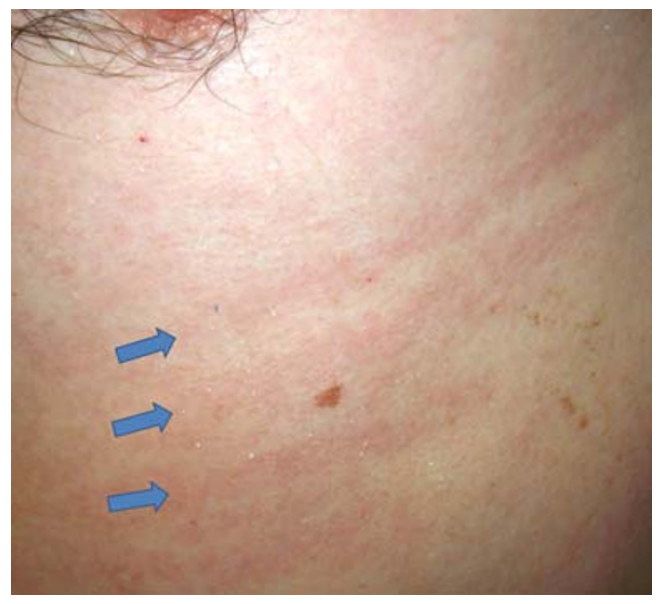

Fig. 1 Three stripes outlining the affected ribs

The views expressed in this paper are those of the author(s) and not those of the editors, editorial board or publisher.

\section{G. N. Cattermole $(\bowtie)$}

Accident and Emergency Medicine Academic Unit,

Prince of Wales Hospital, Chinese University of Hong Kong,

Shatin, Hong Kong

e-mail: gncattermole@cuhk.edu.hk

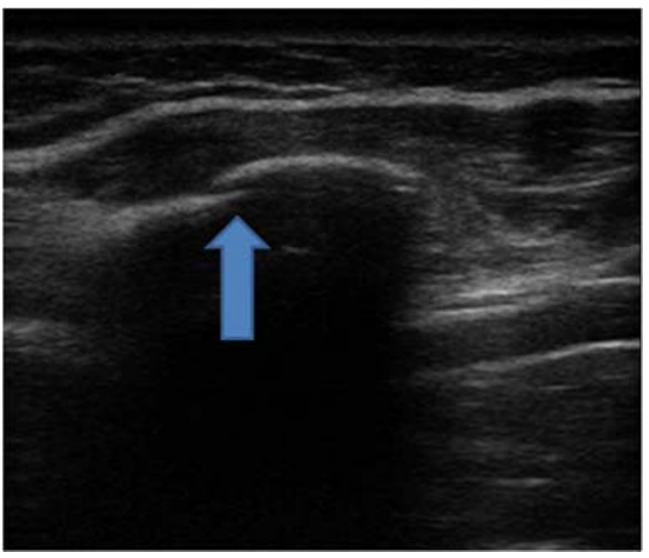

Fig. 2 Ultrasound visualisation of fracture

linear implement and in children would be considered suggestive of maltreatment [1].

In this case it is hypothesised that the linearity was caused by compression of the skin against the tarmac by the ribs from within, rather than by compression by a rod from without. It is likely that such a mechanism requires a body mass substantially greater than the average child's, so although this case demonstrates that linear bruising in an adult is not pathognomonic of a blow with a rod-like implement, in children it will raise suspicion of maltreatment.

\section{Reference}

1. National Collaborating Centre for Women's and Children's Health (2009) When to suspect child maltreatment. RCOG Press, London 